\title{
Postoperative Use of Antibiotics in Adults with Non-perforated Appendicitis Subjected to Open Appendectomy
}

\author{
Mohamed Ali Mlees \\ Department of General Surgery, Faculty of Medicine, Tanta University, Tanta, Egypt
}

Email address:

mohamedmless@gmail.com

\section{To cite this article:}

Mohamed Ali Mlees. Postoperative Use of Antibiotics in Adults with Non-Perforated Appendicitis Subjected to Open Appendectomy. Advances in Surgical Sciences. Vol. 5, No. 3, 2017, pp. 41-44. doi: 10.11648/j.ass.20170503.13

Received: April 2, 2017; Accepted: April 22, 2017; Published: May 31, 2017

\begin{abstract}
Acute appendicitis is the most common cause of acute abdominal pain necessitating appendicectomy. The aim of this study was to determine the role of postoperative antibiotics in non-perforated appendicitis regarding; superficial site infections (SSIs), deep site infections (DSIs), complications and the length of hospital stay. This prospective study was carried out on 112 patients diagnosed as acute appendicitis at the Emergency Hospital, General Surgery Department, Tanta University Hospital from March 2014 to April 2016. The patients classified into two groups: Group 1: patients who received postoperative antibiotics, these included 55 patients and Group 2: patients who did not receive postoperative antibiotics and these included 57 patients. The patients subjected to open appendectomy through a standard Grid-Iron incision. The patients' characteristics, ultrasound findings, antibiotics regimen, operative diagnosis, length of hospital stay, wound infection, complications and histopathological findings were analysed using SPSS V 20. Out of 112 patients, 72 patients were male and 40 patients were female. The patients' age ranged from 18 to 55 years with a mean age of 26 years. There is no significant difference regarding patient's age, sex, medical comorbidities, fever, radiologic findings or operative time between the two groups. Treatment with postoperative antibiotics did not significantly reduce the risk of developing superficial SSIs, DSIs. The patients received postoperative antibiotics were significantly more likely to sustain urinary tract infection $(\mathrm{P}=0.03)$ a postoperative diarrhea $(\mathrm{P}=$ 0.02), increased risk of Clostridium difficile infection $(\mathrm{P}=0.01)$ with higher rates of both readmission $(\mathrm{P}=0.08)$ and reoperation ( $\mathrm{P}=0.07)$ with a significantly longer hospital stay ( $2.6 \mathrm{vs} 1.4$ days, $\mathrm{P}=0.001)$. The use of postoperative antibiotic treatment for nonperforated appendicitis did not reduce the infectious complications while increasing postoperative morbidity and increase the length of hospital stay.
\end{abstract}

Keywords: Postoperative, Antibiotics, Nonperforated, Appendicitis, Complication, SSIs

\section{Introduction}

Acute appendicitis remains the most common cause of acute abdominal pain necessitating appendicectomy. The overall lifetime risk of developing appendicitis is estimated to be of $7 \%$ with the highest incidence occurring between 10 to 30 years. Although the etiology of appendicitis still remains in debate, it results in a blind pouch obstruction. The process can lead to ischemia of the appendiceal wall, perforation with abscess formation, or secondary peritonitis with or without concomitant bacteremia and sepsis [1,2].

The stage of the disease process at the time of operation significantly affects the risk for a postoperative surgical site infection (SSI). These cases are categorized as contaminated (operative wound class III) for acute appendicitis without concomitant perforation or dirty or infected (operative wound class IV) in the case of a ruptured appendix with purulent or feculent contamination. Non-perforated appendicitis has a reported wound infection rate of less than $10 \%$ while perforated appendicitis has an infection rate of $15-20 \%$ [2-5].

Patients with perforated appendicitis are universally given postoperative antibiotics, which is necessary to reduce the complications of wound infection and pelvic abscess, however the use of postoperative antibiotics for preventing infective complications in nonperforated cases is still controversial $[6,7]$. 
Some adverse events are also associated with postoperative antibiotic use like clostridium difficile infection, bacterial resistance and postoperative diarrhea, prolonged hospital stay, increase in financial burden. Many recent researches support the use of single dose preoperative antibiotics in non-perforated appendicitis $[8,9]$.

\section{Patients and Methods}

This prospective study was carried out on 112 patients diagnosed as acute appendicitis at the Emergency Hospital, General Surgery Department, Tanta University Hospital from March 2014 to April 2016. The patients included in the study aged 18 years or more, diagnosed clinically and radiologically (by ultrasound) as acute appendicitis, and operated as an emergency case within 4 hours of admission.

Patients proven to have perforated appendix, appendicular mass, abscess, and all patients who were started as conservative treatment and had received antibiotics within 24 hours of admission were excluded from the study. Also pregnant patients, cases lost to follow-up and patients with a Body Mass Index (BMI) greater than 30 were also excluded.

All the patients received single dose of preoperative intravenous antibiotics (Ceftriaxone 1 gram and Metronidazole 500 milligram) one hour before surgery. The patients were classified into 2 groups: Group 1: patients who received postoperative antibiotics (intravenous Ceftriaxone 1 gram every 12 hours and Metronidazole 500 milligram infusion every 8 hours) for 3 doses, these included 55 patients and Group 2: patients who did not receive postoperative antibiotics and these included 57 patients.

Every patient was subjected to history taking that included: duration of the complaint, presenting symptoms (abdominal pain, fever, anorexia, nausea or vomiting), medication or antibiotics given, general and local abdominal examination and investigations that include: complete blood picture (CBC), C Reactive Protein (CRP), liver function tests, renal function tests, blood glucose estimation, urine analysis and abdominal ultrasound.

All the patients had subjected to appendectomy through a standard Grid-Iron incision, the wound closed without drain using monofilament suture material (3-0 Prolene). The removed appendix sent for histopathological examination. Wound dressing was done in the first postoperative day by Povidone iodine antiseptic solution; stable patients with uneventful postoperative course were discharged in the second postoperative day. Any patient developed wound infection was managed by removing the skin stitches, twice daily dressings, wound swap for culture and sensitivity (C\&S) and immediately starting the patient on postoperative antibiotics (Ceftriaxone and Metronidazole till the result of C\&S). The patients who developed intraperitoneal collection or pelvic abscess were managed initially by ultrasound-guided drainage. Discharge criteria included return of mobility, bowel activity, afebrile status, tolerance of normal diet and pain control.

All patients were followed in the postoperative clinic once every week for one month. The sutures were removed in the 10th postoperative day. The patients' age, sex, presenting symptoms and signs, duration of symptoms, temperature, $\mathrm{CBC}$, ultrasound findings, antibiotics protocol, operative diagnosis, length of hospital stay, wound infection, complications, urinary tract infections, as well as diarrhea and histopathological findings were analysed. Statistical analysis was done using SPSS V 20, univariate and multivariate methods were used in comparing patients who did and did not receive postoperative antibiotics. $\mathrm{P}$ values equal to or less than 0.05 were considered statistically significant.

\section{Results}

In this study, out of 112 patients operated for acute non perforated appendicitis, 72 patients were male and 40 patients were female, a ratio of 1.8:1. The patients' age ranged from 18 to 55 years with a mean age of 26 years, the majority of cases lie in a range between 20-32 years. As shown in Table 1, there is no significant difference regarding patients' age, sex, medical comorbidities (diabetes, liver disease, renal disease, hyperlipidemia, heart disease), fever, leukocytosis, radiologic findings (appendiceal diameter, presence of free fluid) or operative time between the two groups.

Table 1. Patients' characteristics vs postoperative antibiotic treatment.

\begin{tabular}{|c|c|c|c|c|c|}
\hline \multirow{2}{*}{$\begin{array}{l}\text { Variable } \\
\text { Male to female ratio }\end{array}$} & \multicolumn{2}{|c|}{ Postoperative antibiotics $($ Number $=55)$} & \multicolumn{2}{|c|}{ No postoperative antibiotics $($ Number $=57)$} & \multirow{2}{*}{$\frac{\text { P Value }}{0.2}$} \\
\hline & $68: 44$ & & $74: 38$ & & \\
\hline Mean age in years & 25.6 & & 26.4 & & 0.23 \\
\hline Comorbidities & No & $\%$ & No & $\%$ & \\
\hline Diabetes & 2 & $3.6 \%$ & 3 & $5.2 \%$ & 0.67 \\
\hline Hypertension & 7 & $12.7 \%$ & 5 & $8.7 \%$ & 0.3 \\
\hline Hyperlipidemia & 6 & $10.9 \%$ & 4 & $7 \%$ & 0.22 \\
\hline Liver disease & 4 & $7.2 \%$ & 3 & $5.2 \%$ & 0.07 \\
\hline Renal disease & 1 & $1.8 \%$ & 00 & 00 & 0.2 \\
\hline Smoking & 2 & $3.6 \%$ & 3 & $5.2 \%$ & 0.34 \\
\hline Presence of free fluid & 12 & $21.8 \%$ & 10 & $17.5 \%$ & 0.3 \\
\hline Appendiceal diameter in $\mathrm{mm}$ & 11.3 & & 11.6 & & 0.2 \\
\hline WBC & 15.200 & & 14.700 & & 0.08 \\
\hline Admission temperature, ${ }^{\circ} \mathrm{C}$ & 37.2 & & 36.8 & & 0.43 \\
\hline Operating room time in minute & 52 & & 48 & & 0.22 \\
\hline
\end{tabular}


In the present study, regarding the stage of appendicitis, the most common type was suppurative appendicitis (about half of the cases) with strong correlation between operative and histopathological findings (Table 2).

Table 2. Correlation of clinical and pathological stage of appendicitis.

\begin{tabular}{llllll}
\hline \multirow{2}{*}{ Variable } & \multicolumn{3}{l}{ Postoperative antibiotics (Number = 55) } & No postoperative antibiotics (Number = 57) & P Value \\
\cline { 2 - 6 } & No & \% & No & \% & \\
\hline Surgical stage & & & & 42.1 & 0.6 \\
Catarrhal & 23 & 42 & 24 & 49.1 & 0.7 \\
Suppurative & 27 & 49 & 28 & 8.8 & 0.7 \\
Gangrenous & 5 & 9 & 5 & & \\
Pathological stage & & & 22 & 38.6 & 0.6 \\
Catarrhal & 21 & 38.2 & 30 & 52.6 & 0.7 \\
Suppurative & 29 & 52.8 & 5 & 8.8 & 0.7 \\
Gangrenous & 5 & 9 & 5 & \\
\hline
\end{tabular}

In the current study, the patients treated with postoperative antibiotics had a significantly higher rate of the overall infection complications than non-antibiotics group $(12.7 \% \mathrm{VS}$ $7 \%, \mathrm{P}=0.01)$. Treatment with postoperative antibiotics did not significantly reduce the risk of developing superficial SSIs, deep SSIs or organ space SSIs. The patients received postoperative antibiotics were significantly more likely to sustain a postoperative urinary tract infection $(\mathrm{P}=0.03)$, increased risk of Clostridium difficile infection $(\mathrm{P}=0.01)$ and postoperative diarrhea $(\mathrm{P}=0.02)$ while showing higher rates of both readmission $(\mathrm{P}=0.08)$ and reoperation $(\mathrm{P}=0.07)$ (Table 3 ) with a significantly longer postoperative length of stay (2.6 vs 1.4 days, $\mathrm{P}=0.001)$ (Table $1 \& 3$ ).

Table 3. The postoperative complications vs postoperative antibiotic treatment.

\begin{tabular}{|c|c|c|c|c|c|}
\hline \multirow{2}{*}{ Variable } & \multicolumn{2}{|c|}{ Postoperative antibiotics $($ Number $=55)$} & \multicolumn{2}{|c|}{ No postoperative antibiotics $($ Number $=57)$} & \multirow{2}{*}{ P Value } \\
\hline & No & $\%$ & No & $\%$ & \\
\hline Total infectious complications & 7 & 12.7 & 4 & 7 & 0.01 \\
\hline Superficial SSIs & 5 & 9 & 3 & 5.2 & 0.16 \\
\hline Deep SSIs & 2 & 3.6 & 1 & 1.7 & 0.22 \\
\hline Organ-space SSIs & 2 & 3.6 & 1 & 1.7 & 0.12 \\
\hline Wound dehiscence & 1 & 1.8 & 0 & 0.0 & 0.07 \\
\hline Clostridium difficile infection & 3 & 5.4 & 00 & 00 & 0.01 \\
\hline Urinary tract infection & 2 & 3.6 & 0 & 0.0 & 0.03 \\
\hline Readmission & 3 & 5.4 & 1 & 1.7 & 0.08 \\
\hline Reoperation & 1 & 1.8 & 00 & 00 & 0.07 \\
\hline
\end{tabular}

\section{Discussion}

Appendectomy is the most common emergency operation undertaken in general surgery. Postoperative wound Infection can increase the morbidity and increase postoperative pain and sepsis lead to higher rates of hospital readmission with increased length of hospital stay $[10,11,12]$. Patients with perforated appendicitis after appendectomy are usually treated with a variable course of postoperative antibiotics because of heavy contamination of wound and peritoneal cavity however, the role of postoperative antibiotics in reducing the infective complications in non perforated appendicitis is still controversial [7, 13, 14].

In the present study, out of 112 patients operated for acute non perforated appendicitis, 72 patients were male and 40 patients were female, a ratio of 1.8:1. This comparable with the study of Swagata B et al [15] who found male to female ratio was 1.27:1. The patients' age ranged from 18 to 55 years with a mean age of 26 years, the majority of cases lie in a range between 20-32 years. This agrees with the study of Subhajeet et al [16] that showed the mean age was 25.8 years.

In the current study, the incidence of overall postoperative infection complications were $12.7 \%$ for patients treated with postoperative antibiotics and $7 \%$ for non-antibiotic group. This consistent with Winsolow et al [4], Busuttil et al [17] and Liberman et al [18] who reported in their studies that; the infection complications ranged from $0 \%$ to $11 \%$.

In this study, $9 \%$ of patients in antibiotic group and $5.2 \%$ of patients in non-antibiotic group had SSIs, with no statistically significant difference. This agrees with Dr. P. Venkateshwar and Dr. T. Shalini [19] who found no statistically significant difference regarding rate of SSI between patients in antibiotic and non-antibiotic group. Also Liberman et al [18] who randomized 136 patients with nonperforated appendicitis, to receive preoperative cefoxitin, preoperative cefotetan, or combine pre and postoperative cefoxitin. Their analysis concluded that a single-dose of preoperative cefotetan constituted optimal prophylaxis for nonperforated cases.

This also comparable with the study of Mui et al [13] who evaluated the outcomes of 269 patients with nonperforated appendicitis who had been randomized to 1 of 3 separate antibiotic prophylaxis regimens. Specifically, all patients received preoperative cefuroxime plus metronidazole before open appendectomy. Patients then randomized to receive an additional 3 doses of both drugs, an additional 5 days of both 
drugs, and no additional prophylaxis. They concluded that all 3 regimens were equally effective because there were no differences in the rate of postoperative SSI between any of the 3 groups.

Similarly Le et al [14] retrospectively reviewed 507 patients with nonperforated appendicitis who had received adequate preoperative antibiotics, $63 \%$ of whom had received postoperative antibiotics. Their study concluded that; the addition of postoperative antibiotics did not affect the rate of postoperative SSIs in their analysis $(10 \%$ vs $9 \%, \mathrm{P}=0.64)$.

In the present study, the patients who received postoperative antibiotics were statistically more likely to develop a urinary tract infection, statistically significant higher rates of postoperative diarrhea and Clostridium difficile infection. The patients received postoperative antibiotics presented for re-evaluation of these antibioticassociated morbidities, which contributed to the elevated rate of readmissions $(5.4 \%$ vs $1.7 \%, \mathrm{P}=0.08)$ with significantly prolonged postoperative length of hospital stay (2.6 vs 1.4 days, $\mathrm{P}=0.001)$. This coincide with the study of Coakley et al [8] who showed that; in non-perforated appendectomy, the addition of post-operative antibiotics not only failed to add any benefit, but also worsened post-operative morbidity which contributed to the elevated rate of readmissions with prolonged hospital stay and increase in antibiotic-associated diarrhea and treatment cost. Also Bader HS and Hamza AS [20] concluded in their study that; the postoperative broad spectrum antibiotics added financial burden and side effects and had no effect towards preventing wound infection.

\section{Conclusion}

This study suggest that there is no clinical benefit to the use of postoperative antibiotics in patients who have undergone appendicectomy for non-perforated appendicitis. It did not reduce the infectious complications, increase the risk for antibiotic related complications, add to bacterial antibiotic resistance, while increasing postoperative morbidity and increase the length of hospital stay with additional treatment cost.

\section{References}

[1] Vazquez Mohamed AA and Bhat NA: Acute appendicitis dilemma of diagnosis and management. The internet journal of surgery $2010 ; 23(2)$, DOI: $10.5580 / 18 \mathrm{e}$.

[2] Langell JT and Mulvihill SJ: Gastrointestinal perforation and the acute abdomen. Med Clin North Am 2008; 92: 599-625.

[3] Pieper R, Kage L and Nasman P: Acute appendicitis: a clinical study of 1018 cases of emergency appendectomy. Acta Chir Scand 1982; 148: 51-62.

[4] Winsolow RE, Dean RE, Harley JW: Acute nonperforating appendicitis. Arch Surg 1983; 118: 651-654.

[5] Andersson R: Meta-analysis of the clinical and laboratory diagnosis of appendicitis. Br J Surg 2004; 91: 28-37.
[6] Fraser JD, Aguayo P, Leys CM, Keckler SJ, Newland JG, Sharp SW: A complete course of intravenous antibiotics vs. A combination of intravenous and oral antibiotics for perforated appendicitis in children: a prospective randomized trial. Pediatr Surg 2010; 45: 1198-1202.

[7] Ravari H, Jangjoo A, Motamedifar J, Moazzami K: Oral metronidazole as antibiotic prophylaxis for patients with nonperforated appendicitis. Clin Exp Gastroenterol 2011; 4: 273-276.

[8] Coakley BA, Sussman ES, Wolfson TS, Bhagavath AS, Choi JJ, Ranasinghe NE: Postoperative antibiotics correlate with worse outcomes after appendectomy for nonperforated appendicitis. J Am Coll Surg 2011; 213: 778-783.

[9] Malik SA, Rasheed M, Abbasi AS, Iqbal RA, Mian MA: Role of signal dose preoperative antibiotic in acute nonperforated appendicitics. Pak Armed Forces Med J 2013; 63: 114-117.

[10] Department of Health. Hospital episode statistics; England: Financial year 2004-05. Available at www.hesonline.nhs.uk/ Ease/servlet/ ContentServer ? site ID $=1937$ \&categoryID= 202.

[11] Chamisa I: A clinicopathological review of 324 appendices removed for acute appendicitis in Durban, South Africa: a retrospective analysis. Ann R Coll Surg Engl. 2009; 91: 688692.

[12] Bickel A, Gurevits M, Vamos R, Ivry S, Eitan A: Perioperative hyperoxygenation and wound site infection following surgery for acute appendicitis: a randomized, prospective, controlled trial. Arch Surg. 2011; 146: 464-467.

[13] Mui LM, Ng CS, Wong SK: Optimum duration of prophylactic antibiotics in acute nonperforated appendicitis. Aust N Z J Surg 2005; 75: 425-428.

[14] Le D, RusinW, Hill B, Langell J: Post-operative antibiotic use in nonperforated appendicitis. Am J Surg 2009; 198: 748-752.

[15] Swagata B and Ashwini B. Jajee: Alvarado score: A valuble clinical tool for diagnosis of acute appendicitis- a retrospective study. J Med Allied Sci 2013; 3(2): 63-66.

[16] Subhajeet Dey, Pradip K. Mohanta, Anil K. Baruah, Bikram Kharga, Kincho L. Bhutia, Varun K. Singh : Alvarado Scoring in Acute Appendicitis: A Clinicopathological Correlation. Indian J Surg 2010; 72(4): 290-293.

[17] Busuttil RW, Davidson RK, Fine M, Tompkins RK: Effect of prophylactic antibiotics in acute nonperforated appendicitis: a prospective, double-blind clinical study. Ann Surg 1981; 194: 502-509.

[18] Liberman MA, Greason KL, Frame S, Ragland JJ: Single-dose cefotetan or cefoxitin versus multiple-dose cefoxitin as prophylaxis in patients undergoing appendectomy for acute nonperforated appendicitis. J Am Coll Surg 1995; 180: 77-80.

[19] Dr. P. Venkateshwar and Dr. T. Shalini: Post-Operative Use of Antibiotics in Non-Perforated Appendicitis. IOSR Journal of Dental and Medical Sciences 2015; 14(10): 51-54.

[20] Bader HS and Hamza AS: Wound infection in non-perforated acute appendicitis- single dose preoperative antibiotics vs. prophylactic postoperative antibiotics: does it make any difference? International Journal of Research in Medical Sciences 2016; 4(1): 225-230. 